\title{
DEVELOPMENT OF VALVULAR LESIONS IN METASTATIC CARCINOID DISEASE
}

\author{
BY \\ ÅKE THORSON* AND OLOF NORDENFELT \\ From the Department of Medicine (Prof. Jan Waldenström), General Hospital of Malmö, University of Lund, and the
Department of Medicine, County Hospital of Jönköping, Sweden
}

Received April 16, 1958

In recent years there has been a great deal of interest in the so-called carcinoid syndrome. This syndrome has been observed in many cases of carcinoid tumour of the gastro-intestinal tract with extensive metastasis. It consists of certain transient and permanent vaso-motor changes, bronchoconstriction, hyperperistalsis, œdema and ascites, pellagra, and mural and valvular endocardial sclerosis with symptoms and signs of pulmonary and/or tricuspid heart disease. In most reported cases, only some of these components have been evident. It is generally believed that most of the signs and lesions are caused by 5-hydroxy-tryptamine released from the tumour tissue, but the exact mechanisms behind the changes are insufficiently known. The development of endocardial sclerosis in the right side of the heart is especially difficult to explain: though several explanations have been offered, no valid proof has been published in support of any of them. All recent authors agree that the endocardial lesions are acquired late in the course of the tumour disease. However, only a few of the reported patients have been studied before and after the development of their valvular lesions and for this reason the authors believe the present case to be of interest. Our studies include right-heart catheterization during a spontaneous flush episode and verification of the lesions by autopsy. The early history of this patient and some of the hæmodynamic studies have been published (Thorson et al., 1954; Waldenström and Ljungberg, 1955; and Thorson, 1956).

\section{REPORT OF CASE}

A married woman, aged 37 in 1941, was operated on for cholelithiasis, and following this had an acute tonsillitis and arthralgia of short duration. After a brief interval, she again experienced repeated bouts of abdominal pain, which slowly increased in intensity. From 1942 she had also disagreeable hot flushes with a darkish red discoloration of the skin, and from 1948 she had diarrhœa followed by borborygmi. From 1950 she became cyanotic at the end of the flushes, and there appeared lasting venectases over her nose and cheeks. She was troubled by palpitation and tachycardia during the flushes, and from 1952 by a swooning sensation also, at the terminal cyanotic stage of the major flushes. She felt very ill and lost weight and was much troubled by the discoloration and by intense colic with sudden watery stools. She had also slight ankle œdema.

In 1952 one of us (O.N.) suspected a carcinoid tumour of the small intestine from her appearance. A rounded intra-luminar tumour of the jejunum was visualized by X-ray examination and she was operated on by Dr. E. Hasselström, Jönköping, in October 1952. The primary jejunal tumour was resected together with large secondary deposits in the mesentery, the great omentum, the right ovary, and a part of the left ovary. The liver surface was studded with secondary tumours. The tumours removed consisted of typical carcinoid tissue. Immediately after operation the patient was relieved of the spasmodic pain, the diarrhoea and flushes became less frequent and less intense, the œdema disappeared, her appetite improved, and she began to put on weight.

During the following two years there was further slow improvement and she could manage most of her household activities. In the summer of 1954, however, she got slight ankle œdema and dyspnœa on exertion.

* Present address: Danska Vagen 27. Goteborg S, Sweden. 
The cyanosis, which had almost disappeared, returned during the following winter. During the summer of 1955 she got lasting cyanosis and increased diarrhœa, she became decompensated and declined rapidly during the autumn. She died in October 1955 , three years after operation, seemingly from congestive heart failure.

Hamodynamic Investigations. Her heart was examined on several occasions. In September 1952 præcordial auscultation and an electrocardiogram and telerœntgenograms revealed nothing abnormal. No special studies were made during flush episodes.

In February 1953 the heart sounds and the volume and configuration of the heart had not changed and were still normal between the flush episodes. During these, however, there appeared a sequence of hæmodynamic changes. First, when the red colour spread over the skin, the sounds became weak and I, J, and $\mathrm{K}$ waves of the displacement ballistocardiograms became lower than before the flush. Secondly, when the reddening was fully developed and remained stationary the sounds, especially the first sound, became loud and an atrial sound became audible. At the same time, the ballistographic waves became tall, the peripheral pulse strong and fast, and the systolic arterial pressure increased slightly. When the reddening decreased after a couple of minutes and was followed by cyanosis, the first and second heart sounds again became weak and the ballistographic amplitudes became lower than before the onset of the flush. The atrial sound disappeared simultaneously or after a brief interval. The radial pulse felt small.

These changes were found only during sudden intense changes of the skin colour. They were then recognized by auscultation, phonocardiography, and ballistocardiography. The systolic and diastolic blood pressure also varied during the flushes, but less regularly and less intensely. The noted changes were interpreted as showing that the cardiac output first decreased during the rapid spreading of cutaneous hyperæmia, then increased during the stage of constant cutaneous vasodilatation, and again decreased to subnormal values when the cyanosis rapidly increased.

In April 1954, the auricular gallop sound had become constant. It was best heard near the left border of the lower sternum and was evident also between the flush episodes and not only during the height of flush, as was the case in 1953. Also, systolic and presystolic murmurs had developed: they were heard over the third and second intercostal spaces near the left sternal border. The strength of the heart sounds and murmurs, the amplitudes of the $\mathbf{J}$ waves in the ballistogram, the heart rate, and the systemic blood pressure still changed during the flushes in the same way as in 1953; but the changes were thought to be less intense even in flushes with rapid colour changes involving a large area of the skin. Fluoroscopy during several flushes, not done before, showed striking changes of the contractions of the right ventricle and the pulsations of the pulmonary conus. At first, the contractions and pulsations became very small and feeble, then they became large and forceful-looking (when the patient experienced palpitation), and lastly they again became very small until the disappearance of the cyanosis. There were no visible pulsations of the pulmonary vessels. X-ray studies showed an increase of the heart volume at the height of flush. It was thought that the patient now had acquired organic valvular lesions, but she was compensated.

When next seen in November 1954, she had developed ankle œdema, the liver was still larger, and she was more cyanotic. Dyspnœa was present between the flushes also, and she had slight congestive failure. The same murmurs were evident. Again the strength of the sounds and murmurs and the ventricular contractions at fluoroscopy varied with the flushes, but the ballistic amplitudes and the systemic blood pressure no longer changed during the flushes. The resting ballistocardiogram had previously been only slightly abnormal when no flush was present. Now it had become more abnormal. The heart volume between the flush episodes had increased from 460 to $710 \mathrm{ml}$., the right side seemed widened, and the pulmonary conus broadened. There was no post-stenotic dilatation of the pulmonary artery. There was no longer any measurable increase of the heart volume during flushes. The blood pressure remained about 140/95 mm.

At this time a right heart catheterization was performed by Dr. H. Krook. During it the patient had a moderate flush. The intracardiac pressure pulse tracings were similar before and after the flush episode but much changed during the period of vivid red flush.

When there was no flush, the caval and right atrial pressures were normal. The right ventricular diastolic pressure also was normal, but the systolic pressure slightly increased to $39 \mathrm{~mm}$. $\mathrm{Hg}$. At the passage of the pulmonary valve there was a sudden drop of the systolic pressure to 12 to $19 \mathrm{~mm}$. The PCV pressure was normal. There was no evidence of any shunt. The examination showed a moderate stenosis at the site of the pulmonary valve, normal tricuspid function, and competency of the right ventricle (Fig. 1).

Near the end of the second stage of a moderate flush (Fig. 2), the tracings from the right atrium, right ventricle, and pulmonary artery all became di- or tri-phasic. The systolic atrial pressure became raised to about $13 \mathrm{~mm}$., the systolic ventricular pressure became depressed to about $22 \mathrm{~mm}$. with a high end-diastolic pressure, and the pulmonary pressure was almost unchanged. At the same time the diastolic atrial pressure rose slightly, and the hepatic vein pressure with wedged catheter was abnormally high, $15 \mathrm{~mm}$. Hg. These changes were thought to show a functional incompetence of the tricuspid valve, probably also of the 
pulmonary valve, with right ventricular failure and Vorhof Pfropfung. This episode lasted for a few minutes, which allowed tracings to be obtained from three different sites in the right ventricle, from two sites in the atrium, and also from the main trunk and the right branch of the pulmonary artery. During the last artery tracing, the pressure fell slowly and the pulsations became attenuated, but this might have been due to wedging of the catheter tip, clotting, or other technical errors.

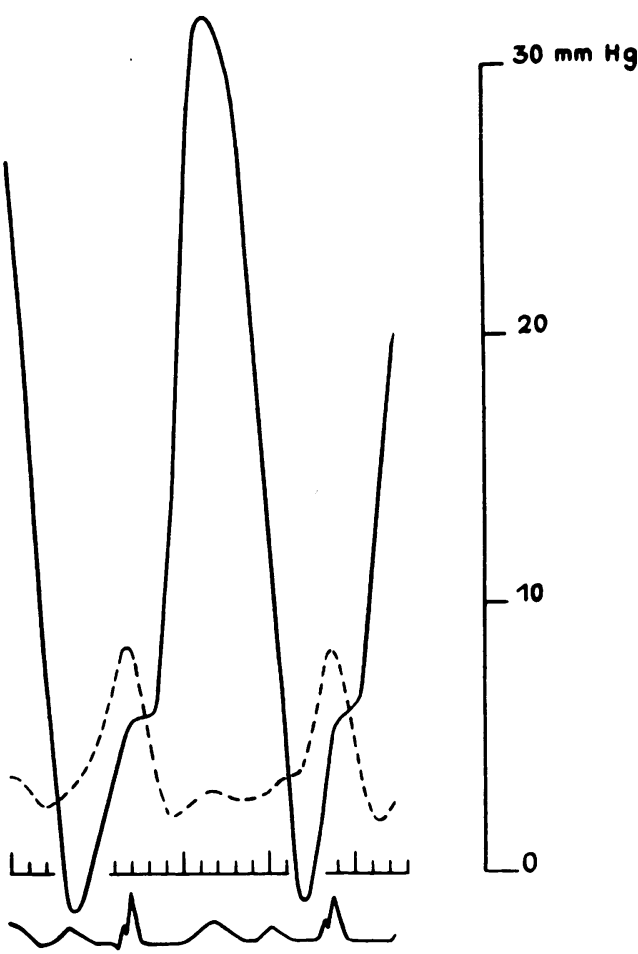

FIG. 1.-Pressure-pulse tracing from the right ventricle a few minutes after the flush had disappeared (the unbroken line). A separately recorded atrial tracing with identical cycle length (the broken line) has been superimposed with the electrocardiogram as time reference. The systolic ventricular pressure is slightly increased, and the atrial pressures are high normal. Both tracings are monophasic.

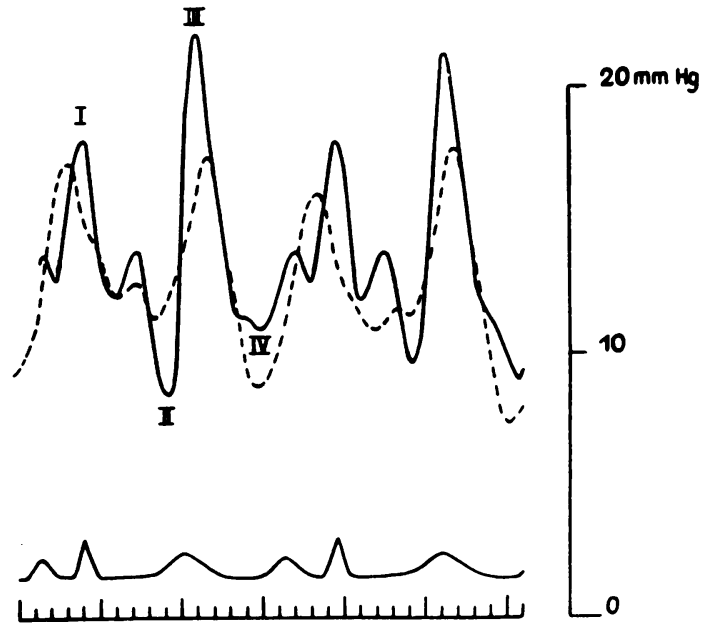

Fig.2.-Pressure-pulse tracings from the right ventricle and the right atrium obtained when the flush had been evident for several minutes (late second stage or beginning of the third stage). Both tracings are biphasic. The systolic ventricular pressure is lowered and the end-diastolic raised. The atrial pressures are now abnormally high. (The period of diastolic filling of the ventricle might have been slightly longer than is apparent in this drawing, as the tracings were not obtained simultaneously but with a brief interval)

The cardiac output was normal before the flush. It could not be measured during the flush, as the patient did not then tolerate breathing into a closed system, and we were not equipped for simultaneous recording of the systemic arterial pressure. Premature beats were noted with the catheter in the ventricle, but otherwise the rhythm was normal.

Valvotomy was not advised and the patient was discharged with digitalis therapy and later with mercurial diuretics which seemed to be beneficial. When last admitted in August 1955 she was more deeply congested, hypotensive, and anæmic, and rapidly developed anasarca during the stay in hospital. The flushes had disappeared, the cyanosis was increased and looked like that in any severe congestive condition. Supportive measures were ineffective, and she died in October 1955, three years after the operation and thirteen years after the first symptoms.

Necropsy Findings (Dr. V. Hederos). There was no recurrence of the primary tumour. Small metastases were found in the great omentum and the mesentery. Numerous almond-sized metastases were found in the right diaphragm. The left ovary was neoplastic and some $6 \mathrm{~cm}$. in diameter. The liver was studded 
with large greyish yellow solid tumours. Other lesions were restricted to the heart. The metastases consisted of carcinoid deposits with argentaffine cells.

The heart was examined by Prof. C. G. Ahlström of Lund. It weighed $300 \mathrm{~g}$. before fixation. The epi- and peri-cardium were fibrotic and adhered to each other. Both atria were slightly dilated, the right ventricle slightly dilated and hypertrophic, and up to $8 \mathrm{~mm}$. in thickness. The mural endocardium was thickened and fibrotic in the right atrium, white and glistening in the left atrium. The tricuspid ostium permitted the passage of two fingers. The leaflets were slightly thickened and fibrous at the free margin, especially near the lateral wall. The tendinous chordæ were severely thickened and shortened. The pulmonary cusps were more severely changed, being low, short, and thickened. The fibrotic change was greatest at the commissures, and propagated as fibrous strands some $10 \mathrm{~mm}$. into the pulmonary artery from the commissures. The pulmonary ostium admitted a little finger. The mitral and aortic valves were of normal size and the cusps were macroscopically intact.

Microscopy. The diffuse thickening of the right atrial endocardium was due to a collagenous connective tissue covered with normal endothelium. The mural endocardium of the left atrium showed thickening and duplication of the elastic layer. The pulmonary cusps were thickened by a pad-like mass of connective tissue on the pulmonary surface of the cusps, which partially filled the valve pockets and spread a

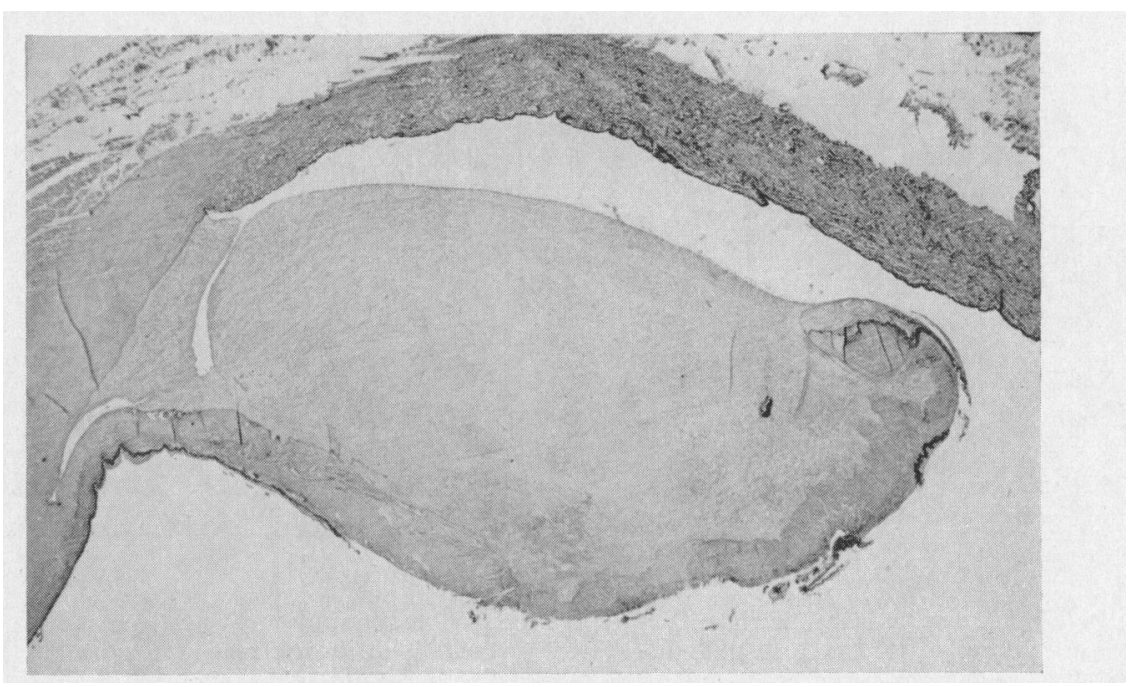

Fig. 3.-Section of a pulmonary cusp. Note the demarcated pad on the pulmonary surface of the cusp. Elastic stain. Magnification: $\times 16$.

short distance on to the pulmonary surface. The pad consisted of loose connective tissue, which in the deeper parts showed numerous slender elastic fibrils and some small vessels. The original elastic layer was laminated (Fig. 3). The tricuspid lesion was mainly similar but less marked. The tendinous chordæ were covered by a broad layer of hyalinous connective tissue with sparse elastic fibrils. The macroscopically normal mitral and aortic valves showed at the microscopic examination a fine nodular fibrotic thickening, each nodule surrounded by numerous slender elastic fibrils. The valves, chordæ and walls were covered with endothelium. There was no inflammatory infiltration. The myocardium seemed normal.

Biochemical Studies. Examinations in 1954 and 1955 by Dr. B. Pernow of Stockholm showed that the amount of 5-hydroxy-tryptamine in the blood serum was abnormally high and that a large amount was present in metastatic tumour tissue obtained at the necropsy.

\section{Discussion}

Several hypotheses have been proposed regarding the mechanisms behind the development of endocardial lesions in patients with the carcinoid syndrome. Thus, Hedinger and Gloor (1954) first mentioned the possibility that the tumour might liberate a substance stimulating connective tissue formation, and Thorson et al. (1954) thought that liberated 5-hydroxy-tryptamine in some 
way caused the endocardial lesions. The simplest explanation, then, would be that the 5-hydroxytryptamine might damage the endocardium and lead to reparatory fibroblastic proliferation, as was originally proposed by Waldenström and Ljungberg (1955) and by Goble et al. (1955). Both these authors were impressed by the high proportion of lesions in the right side of the heart and explained it to be due to the inactivation of a part of the circulating 5-hydroxy-tryptamine during the lung passage with a resulting lower concentration of the substance in the left side of the heart. If this explanation is valid, the 5-hydroxy-tryptamine might damage the endothelium, either by its own action or by acting as a histamine liberator, as might be suggested by the findings of Feldberg and Smith (1953) and of Asboe-Hansen and Wegelius (1956).

Alternatively, Hedinger and Langemann (1955) suggested that platelet deposition on the endocardial surface might occur in carcinoid patients, and in 1956 Goble et al. expressed their opinion that the lesions were due to increased endocardial permeability and platelet deposition on the valve cusps as a result of local 5-hydroxy-tryptamine action.

Goble et al. (1956) refuted the suggestion of Jenkins and Butcher (1955) that increased pulmonary vascular resistance due to constriction of pulmonary arterioles by serotonin (5-hydroxy-tryptamine) was the cause of the valvular sclerosis, because catheterization studies in their patient showed that the previously low cardiac output became moderately raised and the calculated pulmonary resistance slightly lowered during an induced red cutaneous flush. During a following period of bronchoconstriction the output again decreased and the resistance rose slightly but was still within normal limits. Evidently their patient had no signs of pulmonary arterial constriction.

The present patient regularly showed striking hæmodynamic changes during intense flusheschanges that included episodic increase of the venous return and dilatation of the right side of the heart. At catheterization the patient was found to develop tricuspid regurgitation, probable pulmonary regurgitation, and right ventricular failure during a spontaneous flush. She showed no increase of the pulmonary arterial pressure, but no pressure tracings were obtained during the first one or two minutes of the flush, and after that such a change would have been counteracted by the tricuspid regurgitation and right ventricular incompetence. The catheterization in our patient, as well as that in the patient reported by Goble et al., was performed after the development of anatomical valvular disease, when the pulmonary stenosis was functionally evident even with the patient at rest and free from flush. At this advanced stage of the disease any increase of the outflow from the right ventricle would increase the resistance to flow of the pulmonary valve and be counteracted by this. Therefore, the results obtained at the catheterization did not refute the possibility that the pulmonary arterial pressure might have been raised during flush episodes earlier in the course of the disease or even during the first one to two minutes of the examined flush. On the contrary, the findings suggested that this had happened in our patient. The findings in this as well as in three other patients with the carcinoid syndrome and darkish red flushes (Thorson, 1956) showed that periodic dilatation of the right ventricle occurs in at least some of the patients with the syndrome.

The localization and histology of the heart lesions could also suggest that repeated overstretching of the valvular rings and cusps participate in the production of the lesions. The mural endocardial sclerosis probably is secondary to the valvular lesions. Thus, sclerotic thickening visible to the naked eye has only been reported in patients with valvular derangement of functional significance, and, with one exception, only in dilated chambers without muscular hypertrophy or with only slight hypertrophy. The one exception was reported by Millman (1943). As yet no case of carcinoid tumour and pulmonary and/or tricuspid lesions has been reported in a patient who had no flush phenomena or in whom the flushing started after the appearance of reliable signs of the heart lesions. The recorded hæmodynamic changes in this case and in other personal cases seemed to be more violent in the venous part of the circulatory system than in the arterial and this could help to explain the more severe lesions in the right side of the heart.

From the discussion it emerges that there are several possible mechanisms that might participate in the production of the endocardial lesions, namely, sudden distention of the endocardial 
structures in the right side of the heart repeated during several years, a local action of 5-hydroxytryptamine which might alter the endothelial permeability, and deposition of fibrine and platelets on the endothelium. It is also possible that the altered tryptophan metabolism with hypoproteinæmia and hypovitaminosis in carcinoid disease (Sjoerdsma and Udenfriend, 1956) might lower the tissue resistance against trauma, and the higher $\mathrm{CO}_{2}$ tension and lower $\mathrm{O}_{2}$ tension in the right atrium and ventricle could be of some importance for the localization of the lesions.

Regarding treatment after the development of valvular lesions in patients with the carcinoid syndrome, two points should be stressed. First, these patients are seemingly not suited to valvotomy even when it has been possible to remove all tumour tissue. This is due both to the common combination of pulmonary and tricuspid lesions and to the anatomy of the stenosis with shrunken and rigid cusps and, in some cases, fibrous constriction of the annular ring. A valvotomy, then, would only increase the regurgitation, since the small remaining cusps could not close the orifice effectively during diastole after separation at the commissures. Secondly, opiates for alleviation of the diarrhœa should be used only with caution when the patients have a small diuresis. It is possible that treatment with tincture of opium during the final stay in hospital caused the final rapid accumulation of odema and anasarca in our patient. We know of three others who showed great increases of both water retention and flush tendency after a few days' treatment with opiates: in these three the œdema disappeared and the flush tendency decreased when the opiates were withdrawn, and this was repeated several times in one of the patients. The disappearance of the odema in the patients was correlated not with an increased diuresis but with a temporary increase of the diarrhœa.

\section{SUMMARY}

Symptoms, signs, operative findings, and necropsy findings in a woman, aged 51, with a carcinoid tumour of the jejunum and extensive argentaffine metastases are reported. The symptoms had started ten years before the operation and the patient lived for three years after it.

During her last three years hæmodynamic examinations were made at intervals before and after the appearance of signs of pulmonary stenosis and tricuspid regurgitation. The examinations showed a sequence of kinetic changes correlated to the flush episodes.

Catheterization confirmed the pulmonary stenosis. During a spontaneous flush the pressurepulse tracings showed a brief period of tricuspid regurgitation and right ventricular failure.

The pathogenesis of the endocardial sclerosis in the carcinoid syndrome is briefly discussed.

Caution is expressed against operation on the valvular lesions, and against the uncontrolled use of opiates in patients with diarrhœa and a low diuresis.

We wish to express our gratitude to Professor C.-G. Ahlström, Head of the Department of Pathology, the University of Lund, for generous help with the anatomical and histological description of the heart and for the micrograph; to Professor J. Waldenström, Head of the Department of Medicine, Malmö, for the biochemical data; and to Dr. H. Krook, Malmö, for the catheterization data.

\section{REFERENCES}

Asboe-Hansen, G., and Wegelius, O. (1956). Nature, 178, 262.

Feldberg, W., and Smith, A. N. (1953). Brit. J. Pharmacol., 8, 406.

Goble, A. J., Hay, D. R., and Sandler, M. (1955). Lancet, 2, 1016.

- - Hudson, R., and Sandler, M. (1956). Brit. Heart J., 18, 544.

Hedinger, Chr., and Gloor, R. (1954). Schweiz. med. Wchnschr., 84, 942.

-, and Langemann, H. (1955). Schweiz. med. Wchnschr., 85, 368.

Jenkins, J. S., and Butcher, P. J. A. (1955). Lancet, 1, 331.

Millman, S. (1943). Amer. Heart J., 25, 391.

Sjoerdsma, A., and Udenfriend, S. (1955). J. clin. Invest., 34, 914.

Thorson, Å., (1956). Amer. Heart J., 52, 444.

Biörck, G., Björkman, G., and Waldenström, J. (1954). Amer. Heart J., 47, 795.

Waldenström, J., and Ljungberg, E. (1955). Acta. med. Scand., 152, 293. 